\title{
Diagnosis and management of idiopathic pulmonary fibrosis: French practical guidelines
}

\author{
Vincent Cottin, Bruno Crestani, Dominique Valeyre, Benoit Wallaert, \\ Jacques Cadranel, Jean-Charles Dalphin, Philippe Delaval, \\ Dominique Israel-Biet, Romain Kessler, Martine Reynaud-Gaubert, \\ Bernard Aguilaniu, Benoit Bouquillon, Philippe Carré, Claire Danel, \\ Jean-Baptiste Faivre, Gilbert Ferretti, Nicolas Just, Serge Kouzan, \\ François Lebargy, Sylvain Marchand-Adam, Bruno Philippe, Grégoire Prévot, \\ Bruno Stach, Françoise Thivolet-Béjui, Jean-François Cordier and the French \\ National Reference Centre and the Network of Competence Centres for Rare \\ Lung Diseases
}

Affiliations: For a full list of the authors affiliations see the Acknowledgements section.

Correspondence: Vincent Cottin, Hôpital Louis Pradel, Claude Bernard Lyon 1 University, 28 Avenue du Doyen Lepine, 69677 Lyon, France. E-mail: vincent.cottinachu-lyon.fr

ABSTRACT Idiopathic pulmonary fibrosis (IPF) is the most frequent chronic idiopathic interstitial pneumonia in adults. The management of rare diseases in France has been organised by a national plan for rare diseases, which endorsed a network of expert centres for rare diseases throughout France. This article is an overview of the executive summary of the French guidelines for the management of IPF, an initiative that emanated from the French National Reference Centre and the Network of Regional Competence Centres for Rare Lung Diseases. This review aims at providing pulmonologists with a document that: 1) combines the current available evidence; 2) reviews practical modalities of diagnosis and management of IPF; and 3) is adapted to everyday medical practice. The French practical guidelines result from the combined efforts of a coordination committee, a writing committee and a multidisciplinary review panel, following recommendations from the Haute Autorite de Santé. All recommendations included in this article received at least $90 \%$ agreement by the reviewing panel. Herein, we summarise the main conclusions and practical recommendations of the French guidelines.

@ERSpublications

Practical guidelines for idiopathic pulmonary fibrosis are now available http://ow.ly/uUhKh

\section{Introduction}

Idiopathic pulmonary fibrosis (IPF) is a fibroproliferative, irreversible disease of unknown cause. The evolution of IPF is usually progressive, primarily occurring from 60 years of age and is limited to the lungs. It is the most frequent type of chronic idiopathic interstitial pneumonia in adults.

Once considered an orphan disease because no specific treatment with proven efficacy was available, IPF is a rare disease with an estimated prevalence in the USA of between 14 and 28 cases per 100000 population [1].

Received: March 042014 | Accepted after revision: March 172014

Support statement: We received financial support from Fondation partenariale Lyon 1 (Villeurbanne, France).

Conflict of interest: Disclosures can be found alongside the online version of this article at err.ersjournals.com

Provenance: Submitted article, peer reviewed.

Copyright CERS 2014. ERR articles are open access and distributed under the terms of the Creative Commons Attribution Non-Commercial Licence 4.0. 
The annual estimated incidence in the USA is between 6.8 and 8.8 cases per 100000 population [1]. No estimate of the epidemiology of IPF has been published for France.

In France, one national reference centre and nine regional competence centres for rare lung diseases have been endorsed to organise the diagnosis and management of IPF within the general framework of two national plans for rare diseases (2008-2011 and 2013-2016).

Since the publication of international guidelines for the diagnosis and management of IPF in 2011 [2], new data have been published regarding, in particular, the efficacy and tolerance of several new treatments proposed to modify the evolution of the disease or alleviate symptoms. The current aim, coordinated by the reference and competence centres, is to provide pulmonologists with a synopsis of the currently available data and to define as clearly as possible, using terms adapted to real-life daily practice, the modalities of diagnosis and patient-centred management of IPF [3].

The present document is an English version of the executive summary and outlines the main conclusions of the French guidelines for the diagnosis and management of IPF [4].

\section{Missions of the committees}

This article was written by French IPF specialists as a practical overview of the international recommendations for the diagnosis and management of IPF published in 2011 [2], in combination with a critical review of the literature published in this field since 2011, including therapeutic trials. This article was produced by a Coordination committee, a Writing committee and a Reviewing committee.

The committees adopted rules that were applicable to the development of good clinical practice based on the method issued by the Haute Autorite de Santé [5].

\section{Coordination committee}

The Coordination committee submitted the process and validation protocol to the Sociéte de Pneumologie de Langue Française (SPLF), conducted a systematic review of the literature, prepared a first draft of the document intended for the Writing committee, organised the process and validation protocol and monitored its application, and submitted the recommendations validated by the Writing committee and the Reviewing committee to the SPLF.

\section{Writing committee}

The Writing committee assessed the first version of the document prepared by the Coordination committee. Using a three-point scale (I agree, I hesitate or I do not agree) they identified the points to be reviewed, made suggestions about the form and contents of the document, and validated the document to be submitted to the Reviewing committee.

\section{Reviewing committee}

The Reviewing committee comprised three pulmonologists working in a university hospital (excluding the competence centres), three pulmonologists working in a general hospital, three pulmonologists working in private practice, two radiologists with expertise in interstitial lung disease (ILD), and two pathologists who were specialised in thoracic pathology. The committee assessed all the themes and the corresponding recommendations using a scale ranging from 1 (total disagreement) to 9 (total agreement). The vote was conducted electronically and the results were anonymised before analysis. All recommendations submitted to the scrutiny of the Reviewing committee had been approved first by at least $80 \%$ of the Writing committee members [5]. The rating of each statement was based on the synthesis of data published in the literature (which was provided together with the questionnaire) and the experience of the reader in the corresponding field. The members of the Reviewing committee could only answer questions for which they felt competent.

\section{Guidelines development process}

The development of the recommendations comprised the following steps. 1) Critical review of the literature published since 2010 in the field of IPF by the Coordination committee. 2) First version written by the Coordination committee. 3) Review of the first version by the Writing committee. 4) Production of a revised version by the Coordination committee. 5) Review and votes by the Writing committee. 6) Rewriting of issues generating an insufficient consensus level by the Coordination committee. 7) Review and votes by the Reviewing committee. 8) Production of a revised version by the Coordination committee. 9) Review by the SPLF Scientific Council. 10) Production of a revised version by the Coordination committee. 11) Submission of the manuscript. 
The SPLF Scientific Council gave advice on the relevance, writing and applicability of the recommendations. In order to be validated, recommendations had to be approved by at least $90 \%$ of the Reviewing committee members [5].

The recommendations were formulated as follows. 1) "It is recommended" means that the option described is relevant in the majority of patients (e.g. treatment with established efficacy). 2) "It is proposed" means that the option described may be relevant in some patients (e.g. treatment with highly probable efficacy). 3) "It is possible" means that the option described may be relevant in some patients but that available data do not allow a stronger recommendation (e.g. treatment with uncertain efficacy). 4) "It is not recommended" means that the option described is not relevant in the majority of patients (e.g. treatment shown to be inefficient). 5) "It is recommended not to" means that the option described should be avoided (e.g. treatment with harmful effects).

The SPLF Scientific Council approved the methods used to develop these recommendations on January 10, 2013, and approved the written recommendations on June 12, 2013. The recommendations were published in December 2013 [4]. Herein, we summarise the main conclusions and practical recommendations of the French guidelines.

\section{Diagnosis of IPF}

IPF is a fibroproliferative disease of unknown cause, associated with the histopathological and/or highresolution computed tomography (HRCT) pattern of usual interstitial pneumonia (UIP) [2]. The presence of a radiological and/or histological UIP pattern is required to establish the diagnosis of IPF. In patients not subjected to video-assisted surgical lung biopsy (SLB), the diagnosis may be made when an ILD is present (with neither extrapulmonary manifestations nor aetiological context) if HRCT shows a (definite) UIP pattern (fig. 1 and table 1). In patients subjected to video-assisted SLB, the diagnosis is established in the presence of specific combinations of HRCT and SLB aspects showing a UIP pattern (table 2). In all cases, exclusion of other known causes of ILD (in particular those linked to the environment, notably occupational exposure, drug toxicity or systemic disease) is required to establish the diagnosis of IPF.

IPF primarily occurs between 60 and 70 years of age, and is slightly more predominant in males [6-9]. There are no specific clinical signs of IPF, which explains why the diagnosis is often established (too) late. The initial clinical presentation consists of progressive exertional dyspnoea combined with dry cough; bibasilar inspiratory crackles (velcro crackles) are constant and appear early in the disease [2, 10-13]. Finger clubbing is present in $\sim 50 \%$ of cases. Weight loss and alteration of the general status are uncommon. Cyanosis and signs of right ventricular failure only occur in the advanced stages with respiratory insufficiency. The disease progresses towards chronic restrictive respiratory failure and death. Precapillary pulmonary hypertension is often present in advanced stages, in particular if emphysema is associated with IPF.

\section{Question 1: What main causes of diffuse interstitial pneumonia should be clinically investigated in patients considered to potentially have IPF? \\ Recommendation}

It is recommended that a cause of ILD, including exposure to pharmaceutical agents, an inhaled organic antigen or mineral particles, or connective tissue disease and cancer, be clinically investigated in patients for whom a diagnosis of IPF is considered.

\section{Comment}

The diagnosis of IPF requires the exclusion of other forms of ILD [14], including interstitial pneumonias either 1) with an identified cause: hypersensitivity pneumonitis due to inhalation of organic antigen(s), toxicity of pharmaceutical agents, pneumoconiosis caused by a mineral agent (silica and asbestos among others), primary or secondary cancer, or traumatic or haemodynamic pulmonary oedema; or 2) with no identified cause but occurring in a specific context of connective tissue disease (especially rheumatoid arthritis, Sjögren's syndrome and systemic sclerosis), sarcoidosis, a well-defined infiltrative lung disease such as lymphangioleiomyomatosis, pulmonary Langerhans' cell granulomatosis or idiopathic chronic eosinophilic pneumonia, or any other well identified ILD.

\section{Question 2: What biological work-up should be performed in patients considered to have IPF? \\ Recommendation}

It is recommended that biological signs of connective tissue disease be investigated if the diagnosis of IPF is considered. 


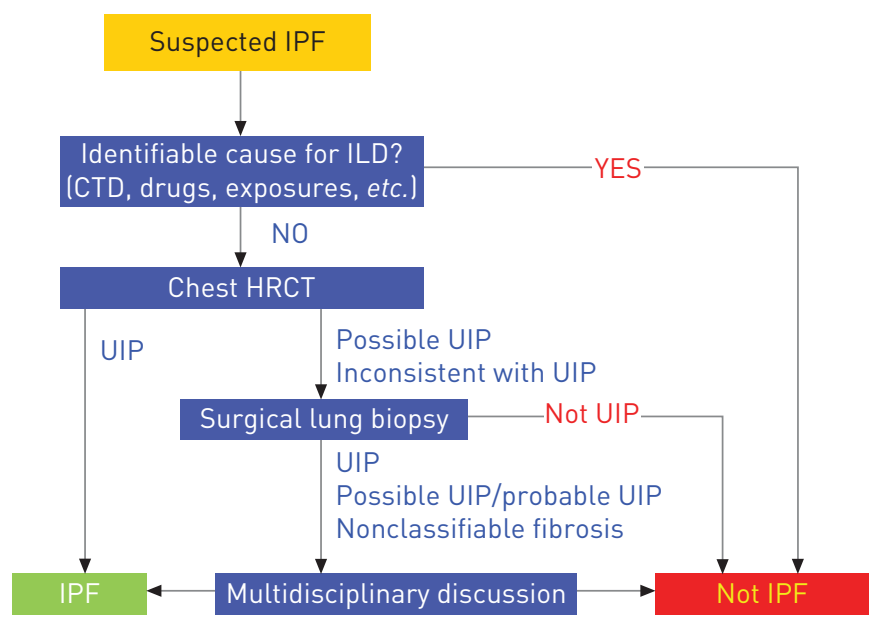

FIGURE 1 Diagnostic algorithm for idiopathic pulmonary fibrosis (IPF). ILD: interstitial lung disease; CTD: connective tissue disease; HRCT: highresolution computed tomography; UIP: usual interstitial pneumonia. Reproduced from [2] with permission from the publisher.

It is proposed that a biological work-up be performed, including determinations of the following. 1) Differential blood cell count, C-reactive protein, serum creatinine, transaminases, $\gamma$-glutamyltransferase and alkaline phosphatases. 2) Anti-nuclear antibodies, anti-citrullinated cyclic peptide antibodies and rheumatoid factor. 3) And depending on the clinical picture or if anti-nuclear antibodies, antibodies specific to Sjögren's syndrome (anti-SSA, anti-SSB), systemic sclerosis antibodies (anti-centromeres, antitopoisomerase-1 and anti-U3RNP), anti-synthetase antibodies, anti-thyroid antibodies, creatine phosphokinase and serum protein electrophoresis are detected.

\section{Comment}

DIP is associated with a radiological and/or pathological pattern compatible with UIP [15], and may be the first clinical manifestation of a connective tissue disease [16]. Therefore, if the diagnosis of IPF is considered it is necessary to systematically look at extrapulmonary signs and biological markers in order to eliminate a connective tissue disease. If signs, symptoms or biological abnormalities suggesting a connective tissue disease occur during the course of the disease, the diagnosis of IPF should be challenged. Biological markers of an inflammatory syndrome or an extrapulmonary disorder should also be measured. Detection of antineutrophil cytoplasmic antibodies has been proposed [17]. Precipitin detection is justified in the case of exposure to organic antigens or if hypersensitivity pneumonitis is suspected. The investigation of infectious agents, in particular by bronchoalveolar lavage (BAL), may be justified. Examinations that aim to identify a lymphoproliferative disorder (protein electrophoresis, immuno-electrophoresis, urinary immunofixation or cryoglobulinaemia) are justified if an ILD other than IPF is suspected.

\section{TABLE 1 High-resolution computed tomography criteria for usual interstitial pneumonia (UIP) pattern}

\section{UIP pattern (all four features)}

Subpleural, basal predominance Reticular abnormality

Honeycombing with or without traction bronchiectasis

Absence of features listed as inconsistent with UIP pattern
Possible UIP pattern (all three features)

Inconsistent with UIP pattern (any of the features)
Subpleural, basal predominance Reticular abnormality

Absence of features listed as inconsistent with UIP pattern
Upper or mid-lung predominance

Peribronchovascular predominance

Extensive ground-glass abnormality lextent $>$ reticular abnormalityl

Profuse micronodules (bilateral, predominantly upper lobes)

Discrete cysts (multiple, bilateral, away from areas of honeycombingl

Diffuse mosaic attenuation/air-trapping (bilateral and in $\geqslant 3$ lobes)

Consolidation in bronchopulmonary segment(s)/lobels)

Reproduced from [2] with permission from the publisher. 
TABLE 2 Diagnosis of idiopathic pulmonary fibrosis (IPF)

HRCT features

UIP

Definite IPF

Possible IPF

Not IPF
Possible UIP

Possible UIP

Inconsistent with UIP

UIP

Possible UIP

Inconsistent with UIP
Pathological features

\author{
No biopsy \\ Definite UIP \\ Probable UIP \\ Possible UIP \\ Unclassifiable fibrosis \\ Definite UIP \\ Probable UIP \\ Possible UIP \\ Unclassifiable fibrosis \\ Definite UIP \\ Non-UIP \\ Non-UIP \\ Probable UIP \\ Possible UIP \\ Unclassifiable fibrosis \\ Not UIP
}

The high-resolution computed tomography (HRCT) criteria for usual interstitial pneumonia (UIP) are listed in table 1. A diagnosis of IPF is made when the HRCT feature is associated with one pathological feature.

\section{Question 3: Should BAL be performed in patients suspected of having IPF? Recommendation}

It is proposed that BAL be performed if the diagnosis of IPF is considered, especially if HRCT does not show a definite UIP pattern.

\section{Comment}

In IPF patients, BAL shows hypercellularity with an increased number of neutrophils and, frequently, an accompanying lower increase of the number of eosinophils. An increased number of lymphocytes evoke a diagnosis other than IPF [18], including chronic hypersensitivity pneumonitis [19], nonspecific interstitial pneumonia (suggesting connective tissue disease) or sarcoidosis. BAL contributes to the diagnosis primarily if the radiological examination does not show a typical UIP pattern, in particular if chronic hypersensitivity pneumonitis is suspected [2]. A predominance of lymphocytes $>30 \%$ does not favour IPF [19].

\section{Question 4: When should genetic testing be performed in patients suspected of having IPF?}

Recommendation

If a diagnosis of IPF is suspected, it is recommended that tests are systematically performed during the medical interview to identify the presence of other causes of ILD within the family, and to search for clinical and biological signs suggesting a genetic cause (hepatic, cutaneous, mucosal and haematological abnormalities).

It is proposed that patients presenting with IPF in a familial context be referred to an outpatient clinic specialising in genetics to establish a pedigree and propose genetic molecular analysis primarily targeting, with the currently available of knowledge, the telomerase complex genes and the surfactant protein-C genes.

\section{Comment}

Familial forms of IPF affecting $<5 \%$ of patients have been reported [20-23]. The probability of a genetic cause seems to be higher in younger individuals (in particular those aged $<50$ years).

Most frequently, the mode of genetic transmission of IPF in those familial cases is an autosomal dominant pattern of inheritance with variable penetrance [21, 22, 24-26]. A congenital form of dyskeratosis, characterised by a mutation of the telomerase complex genes (TERT and TERC), may be suggested by clinical and biological abnormalities, including macrocytosis, refractory anaemia due to erythroblastopenia, cryptogenic hepatic cirrhosis, abnormal cutaneous pigmentation, mucosal abnormalities such as leukoplakia of the tongue margin, or leukotrichia (premature greying of hair) [27]. 


\section{Question 5: What pulmonary function tests should be performed at the time of IPF diagnosis? \\ Recommendation}

It is recommended that forced vital capacity (FVC) and diffusing capacity of the lung for carbon monoxide (DLCO) should be assessed in patients being tested for IPF. It is proposed that total lung capacity, resting arterial blood gas at room air, 6-min walk test (6MWT) distance and percutaneous oxygen saturation should also be assessed.

\section{Comment}

Pulmonary function tests performed at rest in IPF patients show several abnormalities: 1) pulmonary function restrictive pattern (decreased FVC and total lung capacity); 2) early decrease of DLCO and transfer coefficient of the lung for carbon monoxide; and 3) usually, normal arterial blood gas values at rest or hypocapnia (increased alveolar-arterial oxygen tension difference).

In addition, pulmonary function tests performed at exercise show a reduced exercise capacity, which may be assessed by measuring: exercise hypoxaemia (even if not present at rest); the distance walked during a $6 \mathrm{MWT}$; the decrease of percutaneous oxygen saturation during exercise, notably during the 6MWT; and the decrease of maximal consumption of oxygen uptake and maximal power workload during exercise.

\section{Question 6: When is HRCT sufficient for the diagnosis of IPF in patients not subjected to video-assisted SLB? \\ Recommendation}

It is recommended that HRCT findings showing a UIP pattern, in particular a honeycombing pattern (table 2), be considered sufficient to establish the diagnosis of IPF if other causes of ILD have been ruled out.

\section{Comment}

HRCT of the chest is mandatory for the diagnosis of IPF. In $~ 50 \%$ of cases, HRCT shows a definite UIP pattern with honeycombing (fig. 2) [2, 28], which is sufficient for the diagnosis of IPF if the analysis is performed by a team of pulmonologists experienced in the field of IPF in a compatible clinical context. In other cases, the imaging features are not characteristic (fig. 3) and video-assisted SLB is required to establish the diagnosis. In some cases, HRCT findings may be inconsistent with a UIP pattern (fig. 4). Table 2 indicates the criteria used to define HRCT findings as definite or possible UIP. Honeycombing is required to consider a definite UIP pattern on HRCT. Table 3 indicates how HRCT should be performed.

\section{Question 7: In what patients should SLB be considered to establish the diagnosis of} IPF?

\section{Recommendation}

It is recommended that video-assisted SLB be considered in patients for whom the diagnosis of IPF is suspected, if a definite UIP pattern is not present on HRCT. The decision to perform a biopsy is taken during a multidisciplinary team discussion after careful evaluation of the operative risk. The potential risk

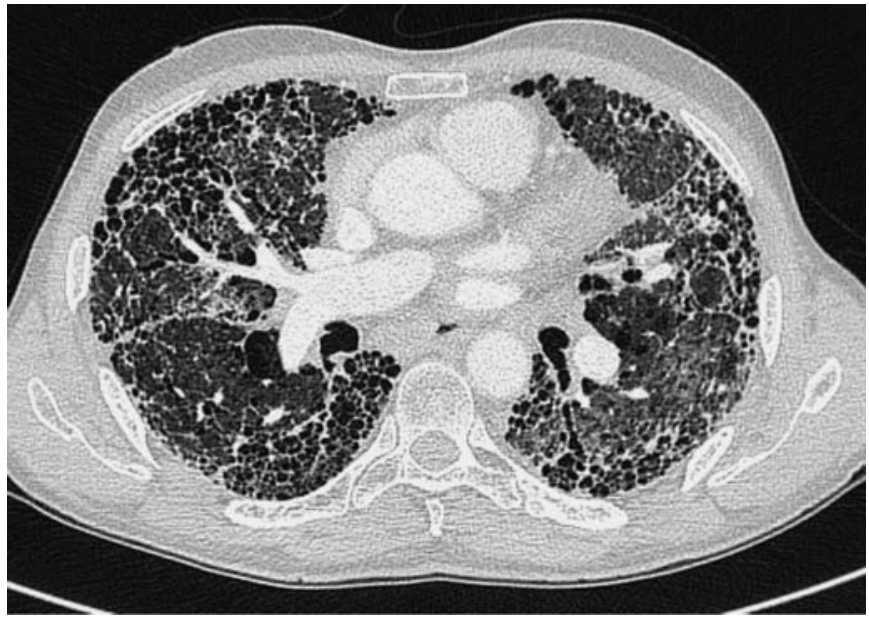

FIGURE 2 High-resolution computed tomography scan demonstrating a typical example of usual interstitial pneumonia pattern with honeycombing change and traction bronchiectasis, as well as subpleural and basal reticulation. No features are seen suggesting an alternative diagnosis. 

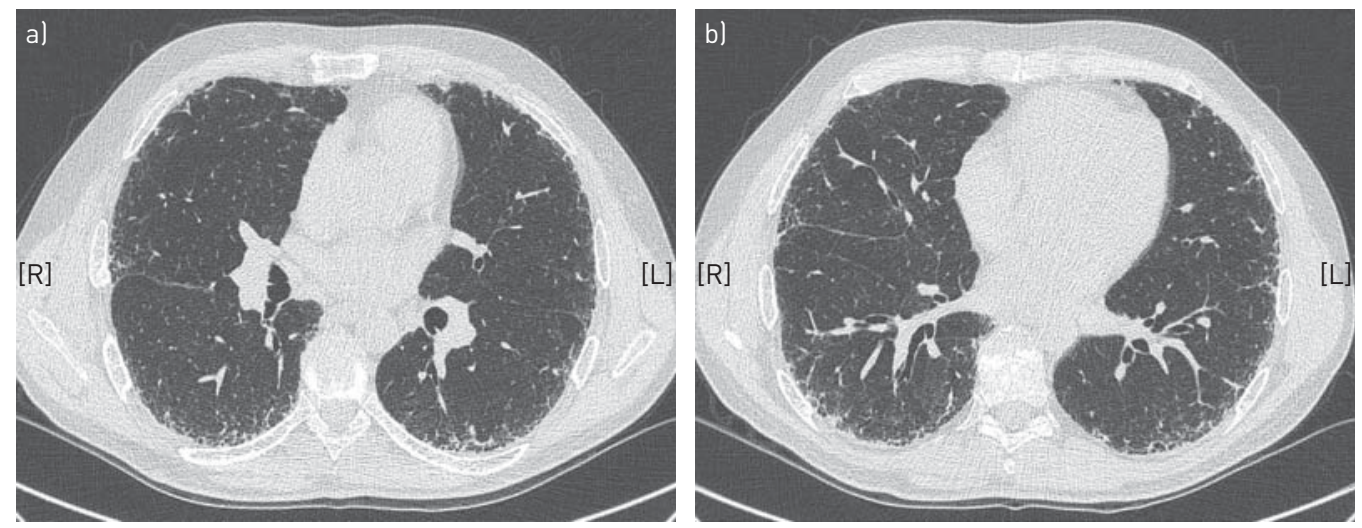

FIGURE 3 a, b) Representative examples of the lung biopsies. High-resolution computed tomography scans demonstrating possible usual interstitial pneumonia pattern with subpleural and basal reticulation, and traction bronchiectasis. No features are seen suggesting an alternative diagnosis. Video-assisted surgical lung biopsy demonstrated definite usual interstitial pneumonia pattern.

associated with biopsy must be taken into account, especially due to the age of the patient, the presence of comorbidities, and the severity and progression of interstitial pneumonia.

\section{Comment}

If the imaging findings are not typical of a UIP pattern, a definite diagnosis of IPF requires a histological UIP pattern to be demonstrated on video-assisted SLB (tables 4 and 5) and is based on the combination of radiological and histological findings [2].

In some cases, HRCT only shows a possible UIP pattern but video-assisted SLB is not performed (because of contraindications or possible risk, or biopsy is not proposed or is declined by the patient). It is then impossible to establish the diagnosis of IPF according to the international recommendation criteria [2].

\section{Question 8: What is the role of multidisciplinary team discussion in the diagnosis of IPF and how is it conducted?}

\section{Recommendation}

During a multidisciplinary discussion involving pulmonologists, radiologists and pathologists experienced in the field of interstitial pneumonias, it is recommended that a definite diagnosis of IPF integrates clinical assessment, computed tomography features and, if available, pathological features (table 1).

It is recommended that complex cases be referred to expert centres (reference or competence centres), or to pulmonology departments experienced in ILDs.

\section{Comment}

The diagnosis of IPF results from the combination of clinical, radiological, biological, respiratory function and, if available, pathological features and is established during multidisciplinary discussion. Ideally, the multidisciplinary discussion takes place in an expert or specialised centre, i.e. the reference centre or one of the competence centres for rare lung diseases, or a pulmonology department experienced in ILDs.

\section{Question 9: How should prognosis be assessed in IPF patients?}

\section{Recommendation}

It is recommended that prognosis be assessed in IPF patients at the time of diagnosis based on: severity of dyspnoea; results of pulmonary function tests (FVC and DLCO); percutaneous oxygen saturation at the end of the 6MWT; extent of honeycombing on HRCT; signs of pulmonary hypertension at echocardiography; and using a score. Prognosis should also be assessed in IPF patients during follow-up based on: progression of symptoms; FVC and DLCO; fibrosis on HRCT; and, where applicable, on signs of pulmonary hypertension at echocardiography.

\section{Comment}

The following factors have been associated with an increased risk of death in IPF patients [29]. 1) Older age and male sex. 2) Early signs and symptoms: including severity of dyspnoea, DLCO $<35-40 \%$ predicted, percutaneous oxygen saturation $<88 \%$ during a $6 \mathrm{MWT}$ at room air, extent of honeycombing on HRCT, 

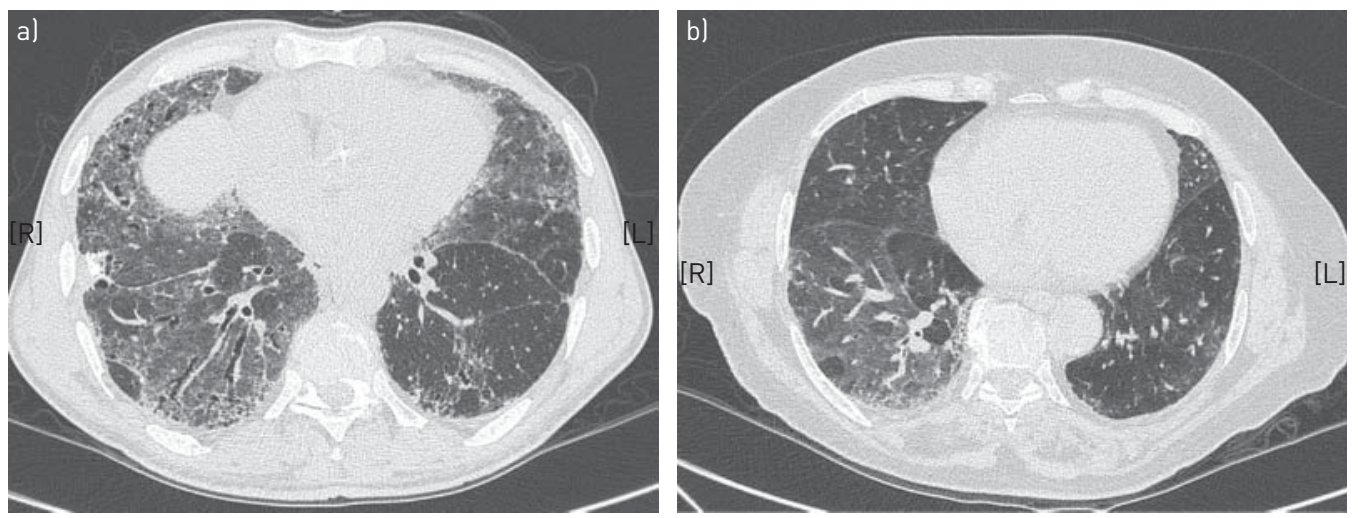

FIGURE 4 High-resolution computed tomography scans demonstrating patterns not consistent with usual interstitial pneumonia. a) Prominent and diffuse ground-glass attenuation with traction bronchiectasis in a patient with idiopathic nonspecific interstitial pneumonia. b) Ground-glass attenuation with mosaic distribution in a patient with hypersensitivity pneumonitis.

and precapillary pulmonary hypertension. 3) Signs and symptoms occurring during the clinical course: including worsening of dyspnoea, $>5 \%$ (absolute value) or $10 \%$ (absolute or relative value) decrease in FVC over 6 months [30], >15\% (absolute or relative value) decrease in DLCO over 6 months, $>50 \mathrm{~m}$ decrease in distance walked during the 6MWT [31], and worsening of fibrosis on HRCT.

The survival estimates at 1,2 and 3 years can be predicted using the GAP (gender, age, physiology) score based on age, sex, FVC and DLCO (www.acponline.org/journals/annals/extras/gap/) [32, 33].

\section{Treatment of IPF}

What medical treatments have been proposed to treat IPF?

Prednisone, azathioprine and $\mathrm{N}$-acetylcysteine triple therapy

Recommendation

It is recommended not to initiate a triple therapy with prednisone, azathioprine and $\mathrm{N}$-acetylcysteine (NAC) in patients definitely diagnosed with IPF.

\section{Comment}

In the randomised, placebo-controlled IFIGENIA(Idiopathic Pulmonary Fibrosis International Group Exploring N-Acetylcysteine I Annual) trial [34], an antioxidant dose $\left(1.8 \mathrm{~g}^{\left.-\mathrm{day}^{-1}\right)}\right.$ of NAC reduced the decrease of FVC and DLCO compared to placebo in a population of IPF patients who were also receiving a combination of prednisone and azathioprine. This trial was not designed to assess the benefits of triple therapy compared to placebo.

\section{TABLE 3 Chest high-resolution computed tomography methods}

\section{Mandatory}

No injection of contrast medium

Inspiratory apnoea slices

Axial contiguous or non-reconstructed slices separated by $\leqslant 2 \mathrm{~cm}$

Slice thickness $\leqslant 2 \mathrm{~mm}$

Reconstruction field focused on lungs

Image acquisition complying with European irradiation norms

Archiving of image acquisition of millimetric slices on CD/DVD for further reading

\section{Optional}

Frontal reconstruction in minimal intensity projection, 5-8 $\mathrm{mm}$ thick ${ }^{\#}$

Images in the prone position, if opacities linked to gravito-dependance hamper the analysis when in the supine position

Expiration slices to exclude lobular air trapping

Coronal and sagittal reconstructions if volumetric acquisitions are available

\#: to differentiate bronchiolectasis from honeycombing; ${ }^{\bullet}$ : more frequent in patients with hypersensitivity pneumonitis. 
TABLE 4 Indications and techniques of lung biopsy in patients with suspected idiopathic pulmonary fibrosis (IPF)

$\begin{array}{ll}\text { Indication } & \begin{array}{c}\text { Absence of HRCT features sufficient to diagnose IPF } \\ \text { Setting }\end{array} \\ \begin{array}{l}\text { Surgical centre experienced in the management of interstitial lung diseases and in } \\ \text { performing video-assisted surgical lung biopsies }\end{array} \\ \begin{array}{l}\text { Technique } \\ \text { Video-assisted surgery whenever possible (excluding transbronchial biopsies) }\end{array} \\ \text { Sampling } & \text { In depth, in several lobes }{ }^{+} \text {, avoiding the extremity of the lingula and middle lobe }\end{array}$

HRCT: high-resolution computed tomography. * : theoretical indication, to be balanced during multidisciplinary team discussion with risk associated with biopsy, age and possible comorbid conditions, and to be discussed with the patient; ${ }^{\text {"}}$ : to collect samples of an adequate size; ${ }^{+}$: lesions may differ between the lobes.

The PANTHER (Prednisolone, Azathioprine and NAC: a study that evaluates response in IPF) trial assessed the efficacy of NAC antioxidant treatment in mild-to-moderate IPF [35]. The trial initially comprised three arms with similar sample sizes (triple therapy: azathioprine + prednisone + NAC versus NAC versus placebo), the main outcome being decrease in FVC at 60 weeks. The triple therapy arm was prematurely discontinued at 6 months after inclusion of 236 patients because of increased risks of all-cause mortality $(\mathrm{p}=0.01)$ and unscheduled hospitalisation $(\mathrm{p}<0.001)$ compared to placebo.

\section{NAC monotherapy \\ Recommendation}

It is possible to prescribe NAC treatment to some patients with a definite diagnosis of IPF, taking into account the benefit/risk ratio and the patient's preferences, if treatment with an approved drug is not indicated after having considered participation in a therapeutic clinical trial.

\section{Comment}

The IFIGENIA trial [34] did not assess the benefits of NAC monotherapy compared to placebo. Results of the ongoing PANTHER trial [35], which currently comprises the NAC and placebo arms, will be released in 2014. Pending the results of ongoing clinical trials, monotherapy treatment with NAC may be considered on

\section{TABLE 5 Histopathological criteria for usual interstitial pneumonia (UIP) pattern

$\begin{array}{lll}\text { UIP pattern (all four features) } \quad \text { Probable UIP pattern } & \begin{array}{c}\text { Possible UIP pattern lall three } \\ \text { features) }\end{array} & \begin{array}{c}\text { Not UIP pattern lany of the } \\ \text { features) }\end{array}\end{array}$

\section{Evidence of marked fibrosis/ architectural distortion thoneycombing in a \\ Evidence of marked fibrosis/ architectural distortion thoneycombing} predominantly subpleural/ paraseptal distribution Presence of patchy involvement of lung parenchyma by fibrosis

Presence of fibroblast foci

Absence of features against a diagnosis of UIP suggesting an alternate diagnosis
Absence of either patchy involvement or fibroblastic foci, but not both Absence of features against a diagnosis of UIP suggesting an alternate diagnosis OR

Honeycomb changes only ${ }^{+}$
Patchy or diffuse involvement of lung parenchyma by fibrosis, with or without interstitial inflammation

Absence of other criteria for UIP

Absence of features against a diagnosis of UIP suggesting an alternate diagnosis
Hyaline membranes ${ }^{\#}$

Organising pneumonia $\#$,

\author{
Granulomas \\ Marked interstitial inflammatory \\ cell infiltrate away from \\ honeycombing \\ Predominant airway-centred \\ changes \\ Other features suggestive of an \\ alternate diagnosis
}

\footnotetext{
\#: can be associated with acute exacerbation of idiopathic pulmonary fibrosis; ${ }^{\bullet}$ : an isolated or occasional granuloma and/or a mild component of organising pneumonia pattern may rarely coexist in lung biopsies with an otherwise UIP pattern; ${ }^{+}$: this scenario usually represents end-stage fibrotic lung disease where honeycombed segments have been sampled but where a UIP pattern might be present in other areas. Such areas are usually represented by overt honeycombing on high-resolution computed tomography (HRCT) and can be avoided by pre-operative targeting of biopsy sites away from these areas using HRCT. Reproduced from [2] with permission from the publisher.
} 
an individual basis. NAC has not been approved for the treatment of IPF and may not be reimbursed by health insurance systems.

\section{Corticosteroid therapy}

Recommendation

It is recommended not to use corticosteroid therapy (with or without immunomodulator therapy) in patients with a definite diagnosis of IPF, except in the context of acute exacerbation of the disease.

Comment

No survival benefit has been demonstrated in patients treated with corticosteroids in controlled trials $[10,36]$. Corticosteroid monotherapy is associated with substantial long-term morbidity [37]. Due to methodological biases [38-40] or conflicting results [41,42] of studies assessing the efficacy of combination corticosteroid and immunomodulator therapy (e.g. azathioprine or cyclophosphamide) on patient's survival, this combination cannot be recommended in the treatment of IPF. Oral corticosteroid therapy up to $10 \mathrm{mg}$ of prednisone per day is sometimes proposed to alleviate incapacitating cough [43]. High-dose corticosteroid therapy is proposed to treat patients with acute exacerbation of IPF.

\section{Anticoagulation therapy}

Recommendation

It is recommended not to prescribe oral anti-vitamin $\mathrm{K}$ anticoagulant agents to treat IPF. While specific data are lacking, oral anti-vitamin $\mathrm{K}$ agents are not contraindicated in patients with IPF if this treatment is indicated for other reasons (especially for cardiovascular indications).

\section{Comment}

A Japanese trial conducted in patients with IPF compared corticosteroid monotherapy to combination corticosteroid and anticoagulant therapy (long-term warfarin treatment; unfractionated or low-molecular weight heparin in hospitalised patients) [44]. Results suggested a survival benefit associated with the combination therapy but the study had major methodological flaws. A more recent and methodologically sound trial comparing warfarin to placebo was prematurely discontinued because of increased mortality $(p=0.005)$ and increased prevalence of adverse events in the warfarin group, without survival benefit [45].

\section{Colchicine, cyclosporine $A$, interferon- $\gamma-1 b$ and etanercept}

Recommendation

It is not recommended to prescribe treatment with colchicine, cyclosporine A, interferon- $\gamma-1 \mathrm{~b}$ or etanercept in patients definitely diagnosed with IPF.

\section{Comment}

Several prospective clinical trials comparing colchicine to various therapeutic regimens did not demonstrate any clinical efficacy of colchicine in IPF [46-48]. A retrospective study conducted in 487 patients with IPF showed no effect of colchicine on survival [10].

In two studies conducted in small groups of patients with IPF, who had received lung transplantation and whose immunosuppressive treatment included cyclosporine, the disease progressed in the nontransplanted lung $[49,50]$.

In two randomised controlled trials, interferon- $\gamma-1 b$ had no effect on disease progression [51] and overall survival [52].

In a randomised controlled trial of etanercept conducted in patients with IPF, no difference was found regarding the primary end-point (change in FVC at 48 weeks) [53].

\section{Endothelin-1 receptor antagonists}

Recommendation

It is not recommended to prescribe treatment with bosentan or macitentan in patients definitely diagnosed with IPF. It is recommended not to prescribe treatment with ambrisentan in patients definitely diagnosed with IPF.

Comment

In a phase II randomised controlled trial of bosentan, an antagonist of endothelin-1 receptors $\mathrm{A}$ and $\mathrm{B}\left(\mathrm{ET}_{\mathrm{A}}\right.$ and $\mathrm{ET}_{\mathrm{B}}$, respectively), there was no improvement in the primary end-point (modified 6MWT) [54]. BUILD (Bosentan Use in Interstitial Lung Disease)-3, conducted in patients with IPF confirmed by lung biopsy [55], did not show any improvement in the primary end-point (time to IPF worsening or death), 
or in quality of life and dyspnoea in the bosentan group. The primary end-point (change in FVC) was also not reached in the MUSIC (Macitentan Use in an Idiopathic Pulmonary Fibrosis Clinical) trial that evaluated macitentan [56], another antagonist of $\mathrm{ET}_{\mathrm{A}}$ and $\mathrm{ET}_{\mathrm{B}}$. In ARTEMIS-IPF [57], ambrisentan, an $\mathrm{ET}_{\mathrm{A}}$ antagonist, had detrimental effects on the primary end-point (time to death or worsening of pulmonary function) and was associated with an increased rate of hospitalisations for respiratory complications. Ambrisentan is currently contraindicated in IPF, including IPF with severe pulmonary hypertension.

\section{Etanercept}

Recommendation

It is not recommended to prescribe treatment with etanercept in patients definitely diagnosed with IPF.

\section{Pirfenidone}

Recommendation

It is currently recommended to treat patients definitely diagnosed with mild-to-moderate IPF (defined as FVC $\geqslant 50 \%$ pred and DLCO $\geqslant 35 \%$ pred) with pirfenidone. This treatment should be initiated and supervised by a physician experienced in the diagnosis and management of IPF, and requires regular monitoring of clinical tolerance and liver enzymes. The patient must not smoke during pirfenidone treatment and patients should be warned against UV exposure.

\section{Comment}

A pooled analysis of two phase III studies (006/Capacity 1 and 004/Capacity 2 ) conducted in patients with mild-to-moderate IPF showed a significant reduction in FVC decline at week 72 in patients treated with pirfenidone [58]. Disease progression (defined as a $\geqslant 10 \%$ decrease in FVC absolute value, a $\geqslant 15 \%$ decrease in DLCO, or death) and decline in 6MWT performance were also reduced. In a phase III study conducted in Japan [59], pirfenidone $\left(1800 \mathrm{mg} \cdot \mathrm{day}^{-1}\right)$ significantly reduced FVC decline compared to placebo. Another phase III trial is ongoing in the USA (www.clinicaltrials.gov; identifier NCT01366209).

Pirfenidone was granted European marketing authorisation in 2011, and was marketed in France in 2012 for the treatment of patients with a clinically and radiologically confirmed diagnosis of mild-to-moderate IPF (FVC $\geqslant 50 \%$ pred and DLCO $\geqslant 35 \%$ pred). Pirfenidone should be initiated and supervised by specialist physicians experienced in the diagnosis and management of IPF.

Pirfenidone should not be administered to patients treated with fluvoxamine and patients with severe hepatic or renal impairment. The most commonly reported adverse reactions with pirfenidone were nausea, rash, fatigue, diarrhoea, dyspepsia, photosensitivity reaction and weight loss [58]. Pirfenidone may also induce elevations in liver enzymes. Liver function tests should be performed prior to the initiation of treatment with pirfenidone, and subsequently at monthly intervals for the first 6 months and every 3 months thereafter.

Smoking has the potential to increase the activity of enzymes involved in pirfenidone metabolism and should be discontinued prior to and during treatment with pirfenidone. Concomitant use of omeprazole may theoretically result in changes in pirfenidone pharmacokinetics and should be avoided.

\section{Should IPF patients be vaccinated against influenza and pneumococcal infections? \\ Recommendation}

It is recommended that annual influenza vaccination and anti-pneumococcal vaccination be performed in patients definitely diagnosed with IPF.

\section{Comment}

Although no specific studies of these vaccinations have been conducted in the context of IPF, it is very likely that, like other patients suffering from chronic respiratory diseases, IPF patients are exposed to a high risk if they develop a pneumococcal infection or influenza. Anti-pneumococcal vaccinations may be performed using the polysaccharide pneumococcal vaccine.

\section{Should IPF patients receive supplemental oxygen therapy? \\ Recommendation}

It is recommended to use long-term oxygen therapy in patients definitely diagnosed with IPF and with severe hypoxaemia at rest (severe chronic respiratory failure).

\section{Comment}

Indirect evidence of benefits of oxygen therapy has been suggested by studies conducted in patients with other lung diseases and hypoxaemia. Two randomised controlled trials have reported a survival benefit in 
patients with chronic obstructive lung disease receiving long-term oxygen therapy [60, 61]. Supplemental oxygen therapy is usually indicated in severe chronic respiratory failure (arterial oxygen tension $\left(\mathrm{PaO}_{2}\right)$ $\leqslant 55 \mathrm{mmHg}(7.3 \mathrm{kPa})$ ), i.e. arterial oxygen saturation $\leqslant 88 \%$ measured at rest in stable conditions on two separate occasions or $\mathrm{PaO}_{2} 55-60 \mathrm{mmHg}(7.3-8.0 \mathrm{kPa})$ if at least one of the following criterion is present: haematocrit $>55 \%$, signs of pulmonary hypertension and documented right heart failure. Long-term oxygen therapy is commonly used in patients with $\mathrm{PaO}_{2} \leqslant 55-60 \mathrm{mmHg}(7.3-8.0 \mathrm{kPa})$ measured at rest in stable conditions on two separate occasions.

\section{Should IPF patients receive respiratory rehabilitation?}

Recommendation

It is proposed that a respiratory rehabilitation programme should be initiated in patients definitely diagnosed with IPF in whom limitation of exercise capacity results in significant impairment.

\section{Comment}

Several studies have reported improvement in walking distance, symptoms or quality of life in IPF patients following a respiratory rehabilitation programme [62, 63]. Respiratory rehabilitation programmes may include exercise training, smoking cessation, psychosocial assistance and supportive care. Rehabilitation may not be feasible in patients with advanced disease.

\section{What is the indication for lung transplantation in IPF patients?}

\section{Recommendation}

It is recommended to consider lung transplantation in all patients definitely diagnosed with IPF aged $<65$ years if the disease is severe or worsening. It is recommended that the patient is given information about lung transplantation early in the course of the disease. Early assessment of the patient in a lung transplantation centre is advised.

\section{Comment}

Lung transplantation improves survival in patients with advanced stage IPF [64-66]. International recommendations specify that transplantation should be considered in patients aged $<65$ years if DLCO is $<39 \%$ pred and FVC has decreased by $\geqslant 10 \%$ over 6 months of follow-up [67]. The (physiological) age limit of $\sim 65$ years is relative and depends on local practice; comorbid conditions should be taken into account.

\section{What are the diagnostic criteria of acute exacerbation of IPF?}

Recommendation

It is recommended to diagnose acute exacerbation of IPF in the case of recent worsening of dyspnoea ( $<30$ days) associated with additional lung opacities on imaging, after other possible causes of respiratory function worsening have been ruled out (i.e. infection, pulmonary embolism and left heart failure).

\section{Comment}

Acute exacerbation of IPF is characterised by acute ( $<30$ days) worsening of dyspnoea with no identified cause (e.g. infection, pulmonary embolism, left heart failure or cardiac arrhythmia) in a patient definitely diagnosed with IPF. HRCT shows new opacities in addition to pre-existing abnormalities, in particular ground-glass opacities. Worsening of hypoxaemia is common $\left(\geqslant 10 \mathrm{mmHg}\right.$ decrease of $\mathrm{PaO}_{2}$ ). Videoassisted SLB is usually considered too hazardous and is not performed in this context.

\section{Which treatments can be suggested to patients with acute exacerbation of IPF?}

\section{Recommendation}

It is proposed to use high-dose corticosteroids to treat acute exacerbations of IPF. It is possible to use intravenous cyclophosphamide to treat acute exacerbations of IPF. There are insufficient data regarding the use of low-molecular weight heparin to treat acute exacerbations of IPF.

\section{Comment}

Although no controlled trials have assessed their efficacy in this indication, high-dose corticosteroids are commonly prescribed to treat exacerbations of IPF [68]. Some observations have suggested that immunosuppressive agents might be beneficial. Cyclosporine A has also been used, but without convincing results. A benefit of intravenous cyclophosphamide has been suggested previously [69].

Low-molecular weight heparins have not demonstrated any benefits in acute exacerbations of IPF, but this treatment is sometimes used. As a trial comparing warfarin to placebo was prematurely discontinued 
because of increased mortality and increased prevalence of adverse events in the warfarin group, without apparent survival benefit [45], long-term oral anticoagulant therapy is not recommended in IPF (see previous section). Wide-spectrum antibiotics may be used when infection has not been definitely ruled out. Anticoagulant therapy may be prescribed in the case of acute worsening of symptoms or if thromboembolic venous disease is suspected.

\section{What is the role of invasive and noninvasive ventilation in the management of IPF? \\ Recommendation}

It is not recommended to use invasive ventilation in patients definitely diagnosed with IPF and acute or chronic respiratory failure. It is possible to use invasive or noninvasive ventilation in a minority of patients with IPF and acute respiratory failure; in particular, if criteria for emergency lung transplantation are met, if exacerbation is the first manifestation of IPF, or in case of acute infection or reversible cause.

\section{Comment}

Given the high mortality associated with mechanical ventilation in IPF [70-79], this therapy should only be used after discussion with the patients and their caregivers (ideally, during a previous visit) regarding goals of care, in particular reduction of unnecessary suffering. Intensive care is justified as a bridge to lung transplantation or if a reversible cause of worsening has been identified [80].

Data on noninvasive ventilation in IPF are scarce. A retrospective study in which some patients with acute exacerbation of IPF were included suggests that, in this context, noninvasive ventilation may be preferred to invasive ventilation without increasing mortality [81].

\section{Should IPF patients be investigated for pulmonary hypertension, if so how? \\ Recommendation}

It is proposed that echocardiography be performed during the IPF diagnostic procedure and then annually to detect pulmonary hypertension in patients with IPF. It is proposed that right heart catheterisation be performed to diagnose pulmonary hypertension in patients definitely diagnosed with IPF: 1) prior to lung transplantation; 2) in cases of clinical deterioration, limitation of exercise capacity, decrease of DLCO (especially if DLCO is $<40 \%$ pred) and/or hypoxaemia disproportionate with regard to the restrictive ventilatory defect (in particular if emphysema is present); 3) if an accurate evaluation of prognosis is deemed essential; 4) if severe precapillary pulmonary hypertension is suspected at echocardiography (tricuspid regurgitation flow $>3.5 \mathrm{~m} \cdot \mathrm{s}^{-1}$ ) and to discuss possible off-label treatment of pulmonary hypertension; and 5) if left ventricular disease with preserved systolic function is suspected.

\section{Comment}

Precapillary pulmonary hypertension (mean pulmonary artery pressure $(P \mathrm{pa}) \geqslant 25 \mathrm{mmHg}$ and pulmonary artery wedge pressure $\leqslant 15 \mathrm{mmHg}$ ) is present in $\sim 10 \%$ of patients with IPF at the time of diagnosis, and $30-45 \%$ during evaluation prior to lung transplantation [82]. Severe pulmonary hypertension (mean $P$ pa $\geqslant 35-40 \mathrm{mmHg}$ ) [83] is present in $2-9 \%$ of patients with IPF [84, 85]. Precapillary pulmonary hypertension is associated with increased mortality [85], dyspnoea and hypoxaemia, decreased exercise capacity and DLCO, and risk of acute exacerbation [86]. Doppler echocardiography is the first-line noninvasive examination but its positive and negative predictive values for the diagnosis of pulmonary hypertension are low [87]. Whether right heart catheterisation is indicated in an IPF patient should be decided in expert centres [82].

\section{How should pulmonary hypertension be managed if present in a patient with IPF? \\ Recommendation}

It is recommended that patients with IPF and pulmonary hypertension are investigated for resting hypoxaemia, thromboembolic venous disease and left heart failure, and that patients receive appropriate treatment if needed. Lung transplantation should also be considered.

In patients with IPF and moderate precapillary pulmonary hypertension (mean $P$ pa $\leqslant 35-40 \mathrm{mmHg}$ at rest), it is not recommended to prescribe any specific treatment for pulmonary hypertension.

In patients with IPF and severe precapillary pulmonary hypertension (mean $P_{\mathrm{pa}} \geqslant 35-40 \mathrm{mmHg}$ at rest), it is possible to prescribe a specific treatment for pulmonary hypertension, preferably with sildenafil in a specialised centre, if pulmonary hypertension is held responsible for worsening of symptoms.

In patients with IPF and severe precapillary pulmonary hypertension (mean $P_{\mathrm{pa}} \geqslant 35-40 \mathrm{mmHg}$ at rest), it is recommended not to prescribe ambrisentan. 
Comment

Causes of pulmonary hypertension other than IPF should always be explored. Lung or heart-lung transplantation should be considered depending on age and comorbid conditions. No treatment specific for pulmonary hypertension is recommended or approved in patients with IPF [83].

In two uncontrolled prospective studies of sildenafil conducted in some patients with IPF and pulmonary hypertension, walk distance and pulmonary haemodynamics improved after 8-12 weeks of treatment $[88,89]$. In the randomised controlled STEP-IPF (Sildenafil Trial of Exercise Performance in IPF) trial, comparing sildenafil therapy and placebo over 12 weeks, no significant improvement of the 6MWT (primary end-point) was observed [90], but sildenafil significantly improved arterial oxygenation, DLCO, dyspnoea and quality of life, and could be useful in patients with right ventricular dysfunction at echocardiography [91].

A randomised controlled trial, ARTEMIS-IPF (www.clinicaltrials.gov; identifier NCT00768300) [57], showed a detrimental effect of ambrisentan, an $\mathrm{ET}_{\mathrm{A}}$ antagonist, on the primary end-point (time to death or worsening of respiratory function) and an increased number of hospitalisations for respiratory complications. This led to premature discontinuation of another trial of ambrisentan in IPF, ARTEMIS-PH (www.clinicaltrials.gov; identifier NCT00879229). Therefore, ambrisentan is contraindicated in IPF patients. An open label study of riociguat in patients with ILD suggested an increase in cardiac output, with unclear clinical benefit [92].

Should IPF patients be investigated for gastro-oesophageal reflux, if so how? How should gastrooesophageal reflux be managed in IPF patients?

Recommendation

It is proposed that a history or symptoms of gastro-oesophageal reflux be investigated during the medical interview of all patients definitely diagnosed with IPF. If gastro-oesophageal reflux is suspected, it is proposed to perform the appropriate tests and to comply with applicable recommendations for gastrooesophageal reflux management.

\section{Comment}

Gastro-oesophageal reflux is common in patients with IPF [93] and is asymptomatic in 50\% of cases [9, 94-96]. Retrospective studies have reported stabilisation of pulmonary function and oxygen requirements in association with medical or surgical treatment of gastro-oesophageal reflux [97]. A survival benefit in IPF patients treated with proton-pump inhibitors or $\mathrm{H} 2$ receptor antagonists has been reported previously [98]. The methodological weaknesses of this study, but also the interest of this research area, have been underlined $[68,99]$.

Available data are insufficient to recommend a particular management of gastro-oesophageal reflux in patients with IPF. The role of surgical treatment and the management of non-acid reflux remain unknown. Pirfenidone-omeprazole combination therapy should be avoided.

Should patients with IPF be investigated for emphysema, if so how? How should emphysema be managed in patients with IPF?

\section{Recommendation}

It is recommended to search for emphysema on the chest HRCT performed for the diagnosis of IPF to avoid underestimation of the severity of the disease if lung volumes are preserved. It is proposed that management of emphysema, if present, should be similar to that of emphysema in other settings, including smoking cessation, and inhaled bronchodilators should be used if airflow obstruction is present. No data are available to support specific drug therapy in the setting of combined pulmonary fibrosis and emphysema.

\section{Comment}

Compared with IPF patients without emphysema, patients with combined pulmonary fibrosis and emphysema have preserved lung respiratory volumes, decreased carbon monoxide transfer and higher oxygen requirement. Disease evolution might be worse in patients with this syndrome compared to those with IPF alone [100, 101], but there are no reliable data showing that emphysema impacts survival. Diagnosis of combined pulmonary fibrosis and emphysema is important so as not to spuriously attribute the preservation of pulmonary volumes to a milder severity of disease. Pulmonary hypertension is particularly frequent and is the main predictor of mortality in patients with the syndrome [102]. Long-term oxygen therapy might be indicated. Monitoring of FVC and DLCO does not allow an accurate assessment of prognosis $[103,104]$. 
No data are available to support recommendation of either specific management of emphysema in IPF patients, or specific management of fibrosis in patients presenting with combined pulmonary fibrosis and emphysema. Possible treatment (pirfenidone and NAC in monotherapy) must be assessed individually, taking into account side-effects, the absence of data on the potential benefit of this treatment in this indication, and the difficulty of evaluating disease evolution (little change in FVC).

\section{Should IPF patients be explored for obstructive sleep apnoea syndrome, if so how?}

Recommendation

It is recommended that ventilatory polygraphy be performed in patients definitely diagnosed with IPF if clinical signs suggest obstructive sleep apnoea syndrome.

\section{Comment}

Several studies have shown a high rate of obstructive sleep apnoea syndrome in patients with IPF [105-107], up to $88 \%$ in a series of 50 patients [108]. Compared to polysomnography, medical interview has a much lower sensitivity to establish the diagnosis. Obesity is not always present. The clinical importance of detecting obstructive sleep apnoea syndrome is not demonstrated in IPF, especially if the syndrome is asymptomatic.

\section{How should obstructive sleep apnoea syndrome be managed in patients with IPF? \\ Recommendation}

No specific data on the management of sleep apnoea in patients with IPF are available. It is proposed that when present in a patient definitely diagnosed with IPF, obstructive sleep apnoea syndrome should be managed with the usual recommendations applicable in patients without IPF.

\section{Comment}

Available data are insufficient to recommend a specific management of obstructive sleep apnoea syndrome in patients with IPF [109].

\section{How should symptoms be managed in patients with IPF?}

Recommendation

It is possible to prescribe a transient, low-dose oral corticosteroid therapy in patients with IPF presenting with incapacitating dry cough not alleviated by codeine. Efficacy and tolerance of this therapy should be monitored.

It is possible to prescribe ambulatory supplemental oxygen therapy in patients definitely diagnosed with IPF presenting with major dyspnoea at exercise and oxygen desaturation at exercise (percutaneous oxygen saturation $<88 \%$ during daily life activities or standardised exercise, such as the 6MWT).

It is possible to prescribe low-dose morphine derivatives in patients with IPF presenting with major dyspnoea, in the absence of hypercapnia, while monitoring the efficacy and tolerance of this treatment.

\section{Comment}

Limited data suggest that oral corticosteroid therapy and thalidomide may alleviate chronic cough associated with IPF. High-dose corticosteroids or thalidomide are poorly tolerated and inadvisable. Lowdose morphine derivatives may be used in cases of major dyspnoea but side-effects of this treatment should be closely monitored [110]. Low-dose morphine derivatives ( $\leqslant 30 \mathrm{mg}$ oral morphine equivalents a day) are not associated with increased mortality in patients with chronic obstructive pulmonary disease and starting long-term oxygen therapy [111]. No similar data are available in patients with IPF.

A small study has suggested that exercise capacity might be improved in patients with IPF and hypoxaemia at rest who were treated with oxygen therapy [112]. Two retrospective studies have shown that ambulatory oxygen therapy may significantly improve 6MWT performance and dyspnoea in patients with IPF $[113,114]$. In those two studies, oxygen flow was increased stepwise until percutaneous oxygen saturation was $\geqslant 88 \%$ in one study and $90 \%$ in the other.

\section{What examinations should be performed and at what frequency during follow-up of an IPF patient? \\ Recommendation}

It is recommended that patients definitely diagnosed with IPF should have a clinical visit and undergo pulmonary function tests, including the measurement of FVC, every 3-6 months. It is proposed that chest computed tomography be performed: if acute exacerbation of IPF is suspected; if unexplained clinical changes occur; if lung cancer is suspected; and prior to lung transplantation. 
Comment

If no other cause can be identified, the following changes suggest worsening of IPF [29, 115]: 1) progressive increase of the level of dyspnoea; 2) progressive decrease of FVC (especially by $\geqslant 10 \%$ of the relative or absolute value); 3) progressive decrease of DLCO (especially by $\geqslant 15 \%$ of the relative or absolute value); 4) worsening of signs of pulmonary fibrosis on computed tomography; 5) acute exacerbation of the disease.

Visits may be repeated every 3-6 months (table 6). Visits to a specialised centre (reference centre, competence centre or hospital department experienced in ILDs) must take place at least annually or more frequently if deterioration occurs. 3 monthly visits may take place in the vicinity of the patient's home, alternating with visits to a specialised centre, preferably in the context of a formal or informal care network involving the treating general practitioner and the treating pulmonologist.

TABLE 6 Main examinations that are useful for idiopathic pulmonary fibrosis (IPF) diagnosis and management

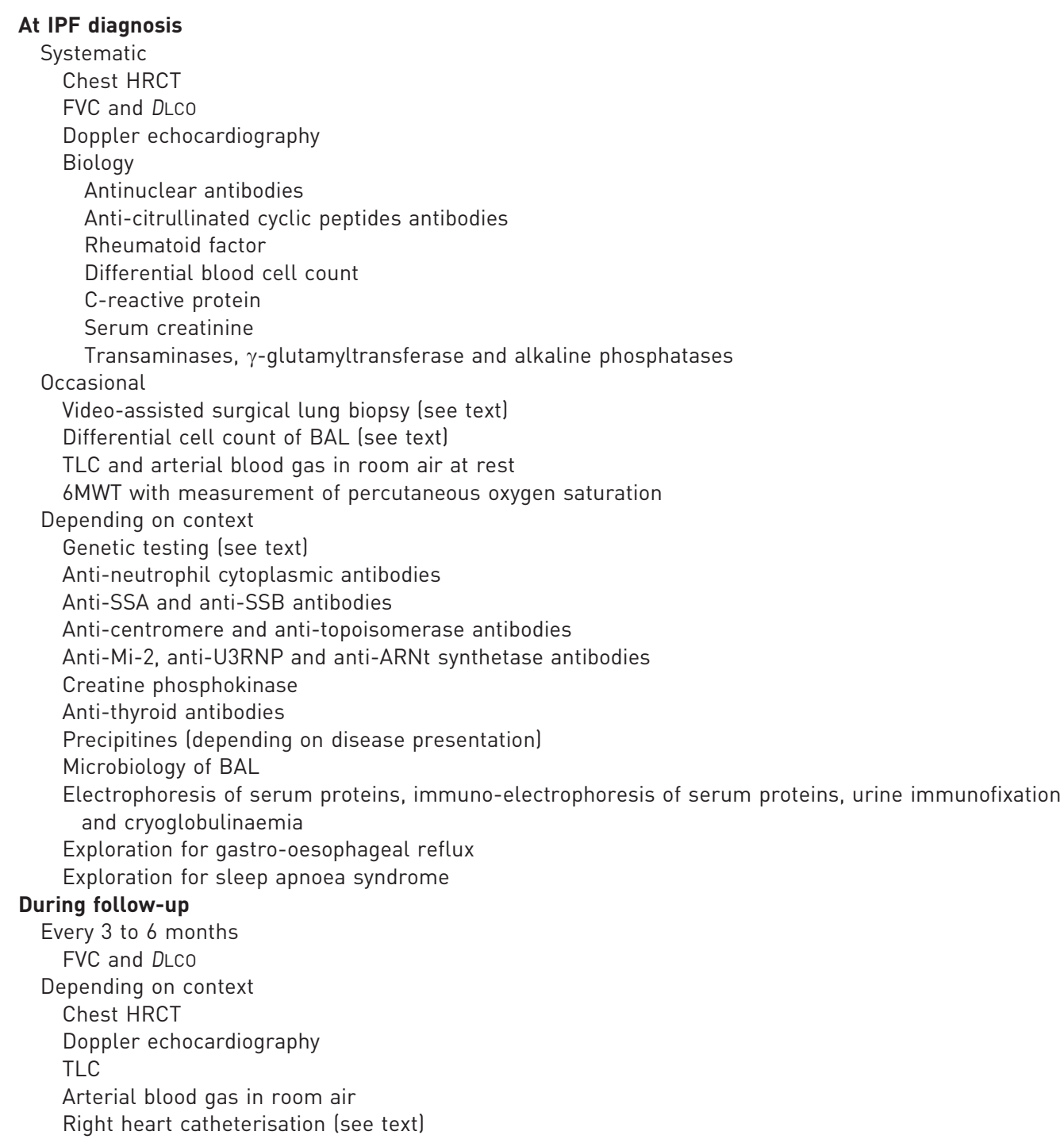

HRCT: high-resolution computed tomography; FVC: forced vital capacity; DLCO: diffusing capacity of the lung for carbon monoxide; BAL: bronchoalveolar lavage; TLC: total lung capacity; 6MWT: 6-min walk test. 


\section{Is the risk of lung cancer increased during follow-up in a patient with IPF? \\ Recommendation}

The risk of lung cancer is increased in patients with IPF. It is proposed that the physician in charge of follow-up be made aware of the frequent occurrence of lung cancer in patients definitely diagnosed with IPF. It is recommended that smokers are urged to quit smoking and are informed about smoking cessation assistance. In patients definitely diagnosed with IPF and lung cancer, it is recommended that IPF is taken into account for treatment decisions.

\section{Comment}

Compared with the risk of lung cancer in the general population, the relative risk of lung cancer in patients with IPF is increased by approximately seven-fold [116]. Lung cancer prevalence in the IPF population is between $4.4 \%$ and $9.8 \%$ [116-118], and a retrospective study reported a 55\% 10-year risk of developing lung cancer [119]. Neither specific screening nor specific management of lung cancer in IPF patients can be recommended.

Lung cancer management is made more difficult by IPF and by the risk of acute respiratory failure and/or acute exacerbation associated with treatments of cancer (surgical resection, radiation therapy and chemotherapy) [120].

\section{Should patients with IPF be investigated for other comorbid conditions?}

Recommendation

It is proposed that comorbid conditions (cardiovascular disease, thromboembolic venous disease, diabetes and depression) be evaluated in patients definitely diagnosed with IPF, in order to inform the physician who is in charge of follow-up.

\section{Comment}

Comorbid conditions, in particular those linked to smoking including cardiovascular disease, thromboembolic venous disease, diabetes and depression, are frequently present in patients with IPF [120]. Available data are insufficient to recommend systematic screening of such comorbid conditions, but informing the physician in charge of follow-up (general practitioner or pulmonologist responsible for the organisation of care) of the presence of a comorbid condition is important.

\section{Conclusion}

Since the ATS/ERS/JRS/ALAT guidelines on the diagnosis and management of IPF were published in 2011, new data from major clinical studies has prompted IPF experts from several European countries to release updated recommendations in the form of national consensus statements or opinions [121, 122].

The need to incorporate recent evidence into recommendations for the diagnosis and management of IPF was the basis of the present document. Our main objective was to provide French pulmonologists with an updated, practical, decision-making tool that could be used in the daily clinical care of patients with suspected or definitely diagnosed IPF.

This document complied with the specific national method and validation processes defined by the Haute Autorité de Santé as good clinical practice for the development of guidelines. The organisation of the three committees with specific missions ensured the involvement of prominent pulmonologists, radiologists and pathologists experienced in the diagnosis and/or management of IPF.

In France, the network of the reference centre and the competence centres for rare lung diseases is responsible for organising the care of patients with rare diseases, including IPF, in collaboration with local pulmonologists, general physicians and other specialists involved in diagnosis and management. These expert centres are geographically spread across all regions of France. The reference centre and the competence centres for rare lung diseases coordinated the entire process of preparation of the present guidelines, in order to standardise and optimise care, but the present recommendations accurately reflect the collective thinking of all the experts involved.

Another feature of the present document is that it gives clinicians guidance even when the compelling evidence for (or against) an examination or treatment is lacking. Formulations such as "It is proposed to" or "It is possible to" accompanied by a summary of the literature justifying these formulations should help the reader to exert informed clinical judgment and decide whether the related diagnostic or therapeutic intervention is appropriate in a given clinical situation.

The main differences between our recommendations and the 2011 guidelines originate from recently emerged evidence. 1) Triple therapy with a prednisone, azathioprine and NAC should not be initiated in 
patients with IPF as it has been shown to increase mortality. 2) Corticosteroid therapy is associated with substantial morbidity and, in combination with immunomodulator therapy, might increase mortality. Corticosteroid therapy is no longer an option for the treatment of IPF, except to alleviate incapacitating cough or to treat acute exacerbation of IPF. 3) Ambrisentan is now contraindicated in the treatment in IPF. 4) To date, pirfenidone is the only pharmacological treatment with demonstrated benefits in IPF patients, and the only treatment that has been approved and granted marketing authorisation for this indication.

We are confident that the present recommendations will help clinicians caring for IPF patients to base their practice on currently available evidence before the much needed updated international guidelines are released.

\section{Acknowledgements}

The author's affiliations are as follows. V. Cottin: Hospices Civils de Lyon, Hôpital Louis Pradel, Service de pneumologie - Centre de référence national des maladies pulmonaires rares, Lyon, and Université de Lyon, Université Claude Bernard Lyon 1, INRA, UMR754 IFR 128, Lyon, France. B. Crestani: Service de Pneumologie, CHU Bichat, Competence Centre for Rare Lung Diseases, Paris, France. D. Valeyre: Dept of Pneumology, Hôpital Universitaire Avicenne, CHU of Bobigny, Competence Centre for Rare Lung Diseases, Bobigny, France. B. Wallaert: CHU of Lille, Competence Centre for Rare Lung Diseases, Lille, France. J. Cadranel: CHU Tenon, Competence Centre for Rare Lung Diseases, Paris, France. J-C. Dalphin: CHU of Besançon, Competence Centre for Rare Lung Diseases, Besançon, France. P. Delaval: CHU of Rennes, Competence Centre for Rare Lung Diseases, Rennes, France. D. Israel-Biet: CHU Georges Pompidou, Competence Centre for Rare Lung Diseases, Paris, France. R. Kessler: CHU of Strasbourg, Competence Centre for Rare Lung Diseases, Strasbourg, France. M. Reynaud-Gaubert: CHU of Marseille, Competence Centre for Rare Lung Diseases, Marseille, France. B. Aguilaniu: Clinique du Mail, Grenoble, France. B. Bouquillon: Opened Mind Health, Roubaix, France. P. Carré: Polyclinique Montréal, Carcassone, France. C. Danel: CHU Bichat, Paris, France. J-B. Faivre: Hôpital Albert Calmette, Lille, France. G. Ferretti: Hôpital Albert Michallon, Grenoble, France. N. Just: Centre Hospitalier Victor Provo, Roubaix, France. S. Kouzan: Centre Hospitalier Intercommunal sud Léman, Saint-Julien-en-Genevois, France. F. Lebargy: Hôpital Maison Blanche, Reims, France. S. Marchand-Adam: CHU de Tours, Service de Pneumologie, CEPR, Inserm U1100, Tours, France. B. Philippe: Centre Hospitalier René Dubos, Pontoise, France. G. Prévot: Hôpital Larrey, Toulouse, France. B. Stach: Cabinet medical, Valenciennes, France. F. Thivolet-Béjui: Centre de biologie et pathogie est, Hôpital Louis Pradel, Lyon, France. J-F. Cordier: Hospices Civils de Lyon, Hôpital Louis Pradel, Service de pneumologie - Centre de référence national des maladies pulmonaires rares, Lyon, France.

The committee members are as follows. Coordination committee: V. Cottin, B. Crestani, D. Valeyre, B. Wallaert and J-F Cordier. Writing committee: V. Cottin, B. Crestani, D. Valeyre, B. Wallaert, J-F. Cordier, J. Cadranel, J-C. Dalphin, P. Delaval, D. Israel-Biet, R. Kessler and M. Reynaud-Gaubert. Reviewing committee: the Writing committee members with the addition of the following. Private practice pulmonologists: P. Carré, B. Stach and B. Aguilaniu. General hospital pulmonologists: N. Just, S. Kouzan and B. Philippe. University hospital pulmonologists: F. Lebargy, S. Marchand-Adam and G. Prévot. Radiologists: G. Ferretti and J-B. Faivre. Pathologists: C. Danel and F. Thivolet-Béjui.

We received support from Opened Mind Health (Roubaix, France) and Michel Bordier (Clamart, France).

\section{References}

Nalysnyk L, Cid-Ruzafa J, Rotella P, et al. Incidence and prevalence of idiopathic pulmonary fibrosis: review of the literature. Eur Respir Rev 2012; 21: 355-361.

2 Raghu G, Collard HR, Egan JJ, et al. An Official ATS/ERS/JRS/ALAT statement: idiopathic pulmonary fibrosis: evidence-based guidelines for diagnosis and management. Am J Respir Crit Care Med 2011; 183: 788-824.

Wuyts WA, Peccatori FA, Russell A-M. Patient-centred management in idiopathic pulmonary fibrosis: similar themes in three communication models. Eur Respir Rev 2014; 23: 231-238.

4 Cottin V, Crestani B, Valeyre D, et al. Recommandations pratiques pour le diagnostic et la prise en charge de la fibrose pulmonaire idiopathique. Elaborées par le Centre national de référence et les Centres de compétence pour les maladies pulmonaires rares sous l'égide de la Société de pneumologie de langue française [French practical guidelines for the diagnosis and management of idiopathic pulmonary fibrosis. From the National Reference and the Competence centers for rare diseases and the Société de Pneumologie de Langue Française]. Rev Mal Respir 2013; 30: 879-902.

5 Haute Autorité de Santé. Élaboration de recommandations de bonne pratique. Méthode. Recommandations pour la pratique clinique. HAS, 2010.

6 Gribbin J, Hubbard RB, Le Jeune I, et al. Incidence and mortality of idiopathic pulmonary fibrosis and sarcoidosis in the UK. Thorax 2006; 61: 980-985.

7 Scott J, Johnston I, Britton J. What causes cryptogenic fibrosing alveolitis? A case-control study of environmental exposure to dust. Br Med J 1990; 301: 1015-1017.

8 Mannino DM, Etzel RA, Parrish RG. Pulmonary fibrosis deaths in the United States, 1979-1991. An analysis of multiple-cause mortality data. Am J Respir Crit Care Med 1996; 153: 1548-1552.

9 Raghu G, Freudenberger TD, Yang S, et al. High prevalence of abnormal acid gastro-oesophageal reflux in idiopathic pulmonary fibrosis. Eur Respir J 2006; 27: 136-142.

10 Douglas WW, Ryu JH, Schroeder DR. Idiopathic pulmonary fibrosis: impact of oxygen and colchicine, prednisone, or no therapy on survival. Am J Respir Crit Care Med 2000; 161: 1172-1178.

11 King TE Jr, Tooze JA, Schwarz MI, et al. Predicting survival in idiopathic pulmonary fibrosis: scoring system and survival model. Am J Respir Crit Care Med 2001; 164: 1171-1181.

12 Cottin V, Cordier JF. Velcro crackles: the key for early diagnosis of idiopathic pulmonary fibrosis? Eur Respir J 2012; 40: 519-521.

13 Bohadana A, Izbicki G, Kraman SS. Fundamentals of lung auscultation. N Engl J Med 2014; 370: 744-751. 
14 American Thoracic Society, European Respiratory Society. American Thoracic Society/European Respiratory Society International Multidisciplinary Consensus Classification of the Idiopathic Interstitial Pneumonias. Am J Respir Crit Care Med 2002; 165: 277-304.

15 Park JH, Kim DS, Park IN, et al. Prognosis of fibrotic interstitial pneumonia: idiopathic versus collagen vascular disease-related subtypes. Am J Respir Crit Care Med 2007; 175: 705-711.

16 Cottin V. Interstitial lung disease: are we missing formes frustes of connective tissue disease? Eur Respir J 2006; 28 : 893-896.

17 Foulon G, Delaval P, Valeyre D, et al. ANCA-associated lung fibrosis: analysis of 17 patients. Respir Med 2008; 102 : 1392-1398.

18 Meyer KC, Raghu G, Baughman RP, et al. An official American Thoracic Society clinical practice guideline: the clinical utility of bronchoalveolar lavage cellular analysis in interstitial lung disease. Am J Respir Crit Care Med 2012; 185: 1004-1014.

19 Ohshimo S, Bonella F, Cui A, et al. Significance of bronchoalveolar lavage for the diagnosis of idiopathic pulmonary fibrosis. Am J Respir Crit Care Med 2009; 179: 1043-1047.

20 Bitterman PB, Rennard SI, Keogh BA, et al. Familial idiopathic pulmonary fibrosis. Evidence of lung inflammation in unaffected family members. N Engl J Med 1986; 314: 1343-1347.

21 Marshall RP, Puddicombe A, Cookson WO, et al. Adult familial cryptogenic fibrosing alveolitis in the United Kingdom. Thorax 2000; 55: 143-146.

22 Hodgson U, Laitinen T, Tukiainen P. Nationwide prevalence of sporadic and familial idiopathic pulmonary fibrosis: evidence of founder effect among multiplex families in Finland. Thorax 2002; 57: 338-342.

23 Lee HL, Ryu JH, Wittmer MH, et al. Familial idiopathic pulmonary fibrosis: clinical features and outcome. Chest 2005; 127: 2034-2041

24 Steele MP, Speer MC, Loyd JE, et al. Clinical and pathologic features of familial interstitial pneumonia. Am J Respir Crit Care Med 2005; 172: 1146-1152.

25 Rosas IO, Ren P, Avila NA, et al. Early interstitial lung disease in familial pulmonary fibrosis. Am J Respir Crit Care Med 2007; 176: 698-705.

26 Musk AW, Zilko PJ, Manners P, et al. Genetic studies in familial fibrosing alveolitis. Possible linkage with immunoglobulin allotypes (Gm). Chest 1986; 89: 206-210.

27 Young NS. Telomere biology and telomere diseases: implications for practice and research. Hematology Am Soc Hematol Educ Program 2010; 2010: 30-35.

28 Cottin V, Capron F, Grenier P, et al. Pneumopathies interstitielles diffuses idiopathiques. Classification de Consensus International Multidisciplinaire de l'American Thoracic Society et de l'European Respiratory Society, principales entités anatomo-cliniques, et conduite du diagnostic [Diffuse idiopathic interstitial pneumonias. International multidisciplinary consensus classification by the American Thoracic Society and the European Respiratory Society, principal clinico-pathological entities, and diagnosis]. Rev Mal Respir 2004; 21: 299-318.

29 Ley B, Collard HR, King TE Jr. Clinical course and prediction of survival in idiopathic pulmonary fibrosis. Am J Respir Crit Care Med 2011; 183: 431-440.

30 du Bois RM, Weycker D, Albera C, et al. Forced vital capacity in patients with idiopathic pulmonary fibrosis: test properties and minimal clinically important difference. Am J Respir Crit Care Med 2011; 184: 1382-1389.

31 du Bois RM, Weycker D, Albera C, et al. Six-minute-walk test in idiopathic pulmonary fibrosis: test validation and minimal clinically important difference. Am J Respir Crit Care Med 2011; 183: 1231-1237.

32 du Bois RM, Weycker D, Albera C, et al. Ascertainment of individual risk of mortality for patients with idiopathic pulmonary fibrosis. Am J Respir Crit Care Med 2011; 184: 459-466.

33 Ley B, Ryerson CJ, Vittinghoff E, et al. A multidimensional index and staging system for idiopathic pulmonary fibrosis. Ann Intern Med 2012; 156: 684-691.

34 Demedts M, Behr J, Buhl R, et al. IFIGENIA: effects of $N$-acetylcysteine (NAC) on primary end points VC and DL,CO. Eur Respir J 2004; 24: Suppl. 48s, 668s.

35 Raghu G, Anstrom KJ, King TE Jr, et al. Prednisone, azathioprine, and $\mathrm{N}$-acetylcysteine for pulmonary fibrosis. N Engl J Med 2012; 366: 1968-1977.

36 Nagai S, Kitaichi M, Hamada K, et al. Hospital-based historical cohort study of 234 histologically proven Japanese patients with IPF. Sarcoidosis Vasc Diffuse Lung Dis 1999; 16: 209-214.

37 Gay SE, Kazerooni EA, Toews GB, et al. Idiopathic pulmonary fibrosis: predicting response to therapy and survival. Am J Respir Crit Care Med 1998; 157: 1063-1072.

38 Winterbauer RH, Hammar SP, Hallman KO, et al. Diffuse interstitial pneumonitis. Clinicopathologic correlations in 20 patients treated with prednisone/azathioprine. Am J Med 1978; 65: 661-672.

39 Raghu G, Depaso WJ, Cain K, et al. Azathioprine combined with prednisone in the treatment of idiopathic pulmonary fibrosis: a prospective double-blind, randomized, placebo- controlled clinical trial. Am Rev Respir Dis 1991; 144: 291-296.

40 Johnson MA, Kwan S, Snell NJ, et al. Randomised controlled trial comparing prednisolone alone with cyclophosphamide and low dose prednisolone in combination in cryptogenic fibrosing alveolitis. Thorax 1989; 44: 280-288.

41 Collard HR, Ryu JH, Douglas WW, et al. Combined corticosteroid and cyclophosphamide therapy does not alter survival in idiopathic pulmonary fibrosis. Chest 2004; 125: 2169-2174.

42 Pereira CA, Malheiros T, Coletta EM, et al. Survival in idiopathic pulmonary fibrosis-cytotoxic agents compared to corticosteroids. Respir Med 2006; 100: 340-347.

43 Hope-Gill BD, Hilldrup S, Davies C, et al. A study of the cough reflex in idiopathic pulmonary fibrosis. Am J Respir Crit Care Med 2003; 168: 995-1002.

44 Kubo H, Nakayama K, Yanai M, et al. Anticoagulant therapy for idiopathic pulmonary fibrosis. Chest 2005; 128: $1475-1482$.

45 Noth I, Anstrom KJ, Calvert SB, et al. A placebo-controlled randomized trial of warfarin in idiopathic pulmonary fibrosis. Am J Respir Crit Care Med 2012; 186: 88-95.

46 Fiorucci E, Lucantoni G, Paone G, et al. Colchicine, cyclophosphamide and prednisone in the treatment of mildmoderate idiopathic pulmonary fibrosis: comparison of three currently available therapeutic regimens. Eur Rev Med Pharmacol Sci 2008; 12: 105-111. 
Antoniou KM, Nicholson AG, Dimadi M, et al. Long-term clinical effects of interferon gamma-1b and colchicine in idiopathic pulmonary fibrosis. Eur Respir J 2006; 28: 496-504.

48 Douglas WW, Ryu JH, Swensen SJ, et al. Colchicine versus prednisone in the treatment of idiopathic pulmonary fibrosis. A randomized prospective study. Members of the Lung Study Group. Am J Respir Crit Care Med 1998; 158: 220-225.

49 Grgic A, Lausberg H, Heinrich M, et al. Progression of fibrosis in usual interstitial pneumonia: serial evaluation of the native lung after single lung transplantation. Respiration 2008; 76: 139-145.

50 Wahidi MM, Ravenel J, Palmer SM, et al. Progression of idiopathic pulmonary fibrosis in native lungs after single lung transplantation. Chest 2002; 121: 2072-2076.

51 Raghu G, Brown KK, Bradford WZ, et al. A placebo-controlled trial of interferon- $\gamma$-1b in patients with idiopathic pulmonary fibrosis. N Engl J Med 2004; 350: 125-133.

52 King TE Jr, Albera C, Bradford WZ, et al. Effect of interferon- $\gamma-1 \mathrm{~b}$ on survival in patients with idiopathic pulmonary fibrosis (INSPIRE): a multicentre, randomised, placebo-controlled trial. Lancet 2009; 374: $222-228$.

53 Raghu G, Brown KK, Costabel U, et al. Treatment of idiopathic pulmonary fibrosis with etanercept: an exploratory, placebo-controlled trial. Am J Respir Crit Care Med 2008; 178: 948-955.

54 King TE Jr, Behr J, Brown KK, et al. BUILD-1: a randomized placebo-controlled trial of bosentan in idiopathic pulmonary fibrosis. Am J Respir Crit Care Med 2008; 177: 75-81.

55 King TE Jr, Brown KK, Raghu G, et al. BUILD-3: a randomized, controlled trial of bosentan in idiopathic pulmonary fibrosis. Am J Respir Crit Care Med 2011; 184: 92-99.

56 Raghu G, Million-Rousseau R, Morganti A, et al. Efficacy and safety of macitentan in idiopathic pulmonary fibrosis: results of a prospective, randomized, double-blind, placebo-controlled trial. Am J Respir Crit Care Med 2012; 185: A3631.

57 Raghu G, Behr J, Brown KK, et al. ARTEMIS-IPF: a placebo-controlled trial of ambrisentan in idiopathic pulmonary fibrosis. Am J Respir Crit Care Med 2012; 185: A3632.

58 Noble PW, Albera C, Bradford WZ, et al. Pirfenidone in patients with idiopathic pulmonary fibrosis (CAPACITY): two randomised trials. Lancet 2011; 377: 1760-1769.

59 Taniguchi H, Ebina M, Kondoh Y, et al. Pirfenidone in idiopathic pulmonary fibrosis. Eur Respir J 2010; 35: 821-829.

60 Continuous or nocturnal oxygen therapy in hypoxemic chronic obstructive lung disease: a clinical trial. Nocturnal Oxygen Therapy Trial Group. Ann Intern Med 1980; 93: 391-398.

61 Long term domiciliary oxygen therapy in chronic hypoxic cor pulmonale complicating chronic bronchitis and emphysema. Report of the Medical Research Council Working Party. Lancet 1981; 1: 681-686.

62 Holland AE, Hill CJ, Conron M, et al. Short term improvement in exercise capacity and symptoms following exercise training in interstitial lung disease. Thorax 2008; 63: 549-554.

63 Nishiyama O, Kondoh Y, Kimura T, et al. Effects of pulmonary rehabilitation in patients with idiopathic pulmonary fibrosis. Respirology 2008; 13: 394-399.

64 Mason DP, Brizzio ME, Alster JM, et al. Lung transplantation for idiopathic pulmonary fibrosis. Ann Thorac Surg 2007; 84: 1121-1128.

65 Keating D, Levvey B, Kotsimbos T, et al. Lung transplantation in pulmonary fibrosis: challenging early outcomes counterbalanced by surprisingly good outcomes beyond 15 years. Transplant Proc 2009; 41: 289-291.

66 Thabut G, Mal H, Castier Y, et al. Survival benefit of lung transplantation for patients with idiopathic pulmonary fibrosis. J Thorac Cardiovasc Surg 2003; 126: 469-475.

67 Orens JB, Estenne M, Arcasoy S, et al. International guidelines for the selection of lung transplant candidates: 2006 update - a consensus report from the Pulmonary Scientific Council of the International Society for Heart and Lung Transplantation. J Heart Lung Transplant 2006; 25: 745-755.

68 Raghu G. Idiopathic pulmonary fibrosis: increased survival with "gastroesophageal reflux therapy": fact or fallacy? Am J Respir Crit Care Med 2011; 184: 1330-1332.

69 Morawiec E, Tillie-Leblond I, Pansini V, et al. Exacerbations of idiopathic pulmonary fibrosis treated with corticosteroids and cyclophosphamide pulses. Eur Respir J 2011; 38: 1487-1489.

70 Blivet S, Philit F, Sab JM, et al. Outcome of patients with idiopathic pulmonary fibrosis admitted to the ICU for respiratory failure. Chest 2001; 120: 209-212.

71 Kim DS, Park JH, Park BK, et al. Acute exacerbation of idiopathic pulmonary fibrosis: frequency and clinical features. Eur Respir J 2006; 27: 143-150.

72 Molina-Molina M, Badia JR, Marin-Arguedas A, et al. Características clínicas y pronóstico de los pacientes con fibrosis pulmonar que ingresan en cuidados intensivos por insuficiencia respiratoria. Análisis de 20 casos [Outcomes and clinical characteristics of patients with pulmonary fibrosis and respiratory failure admitted to an intensive care unit. A study of 20 cases]. Med Clin (Barc) 2003; 121: 63-67.

73 Saydain G, Islam A, Afessa B, et al. Outcome of patients with idiopathic pulmonary fibrosis admitted to the intensive care unit. Am J Respir Crit Care Med 2002; 166: 839-842.

74 Nava S, Rubini F. Lung and chest wall mechanics in ventilated patients with end stage idiopathic pulmonary fibrosis. Thorax 1999; 54: 390-395.

75 Stern JB, Mal H, Groussard O, et al. Prognosis of patients with advanced idiopathic pulmonary fibrosis requiring mechanical ventilation for acute respiratory failure. Chest 2001; 120: 213-219.

76 Al-Hameed FM, Sharma S. Outcome of patients admitted to the intensive care unit for acute exacerbation of idiopathic pulmonary fibrosis. Can Respir J 2004; 11: 117-122.

77 Fumeaux T, Rothmeier C, Jolliet P. Outcome of mechanical ventilation for acute respiratory failure in patients with pulmonary fibrosis. Intensive Care Med 2001; 27: 1868-1874.

78 Mollica C, Paone G, Conti V, et al. Mechanical ventilation in patients with end-stage idiopathic pulmonary fibrosis. Respiration 2010; 79: 209-215.

79 Rangappa P, Moran JL. Outcomes of patients admitted to the intensive care unit with idiopathic pulmonary fibrosis. Crit Care Resusc 2009; 11: 102-109.

80 Mullier A, Cottin V, Richard J-C, et al. Fibrose pulmonaire: dans quels cas et sur quels critères envisager une admission en réanimation? [Pulmonary fibrosis: which patient should be admitted to the ICU and based on which critera?]. Réanimation 2013; 22: 45-53. 
81 Yokoyama T, Kondoh $\mathrm{Y}$, Taniguchi $\mathrm{H}$, et al. Noninvasive ventilation in acute exacerbation of idiopathic pulmonary fibrosis. Intern Med 2010; 49: 1509-1514.

82 Nathan SD, Cottin V. Pulmonary hypertension in patients with idiopathic pulmonary fibrosis. In: Hoeper MH, Humbert M, eds. Pulmonary Hypertension. ERS Monogr 2012; 57: 148-160.

83 Seeger W, Adir Y, Barbera JA, et al. Pulmonary hypertension in chronic lung diseases. J Am Coll Cardiol 2013; 62: Suppl. 25, D109-D116.

84 Shorr AF, Wainright JL, Cors CS, et al. Pulmonary hypertension in patients with pulmonary fibrosis awaiting lung transplant. Eur Respir J 2007; 30: 715-721.

85 Lettieri CJ, Nathan SD, Barnett SD, et al. Prevalence and outcomes of pulmonary arterial hypertension in advanced idiopathic pulmonary fibrosis. Chest 2006; 129: 746-752.

86 Judge EP, Fabre A, Adamali HI, et al. Acute exacerbations and pulmonary hypertension in advanced idiopathic pulmonary fibrosis. Eur Respir J 2012; 40: 93-100.

87 Arcasoy SM, Christie JD, Ferrari VA, et al. Echocardiographic assessment of pulmonary hypertension in patients with advanced lung disease. Am J Respir Crit Care Med 2003; 167: 735-740.

88 Madden BP, Allenby M, Loke TK, et al. A potential role for sildenafil in the management of pulmonary hypertension in patients with parenchymal lung disease. Vascul Pharmacol 2006; 44: 372-376.

89 Collard HR, Anstrom KJ, Schwarz MI, et al. Sildenafil improves walk distance in idiopathic pulmonary fibrosis. Chest 2007; 131: 897-899.

90 Zisman DA, Schwarz M, Anstrom KJ, et al. A controlled trial of sildenafil in advanced idiopathic pulmonary fibrosis. N Engl J Med 2010; 363: 620-628.

91 Han MK, Bach DS, Hagan P, et al. Sildenafil preserves exercise capacity in IPF patients with right ventricular dysfunction. Chest 2013; 143: 1699-1708.

92 Hoeper MM, Halank M, Wilkens $\mathrm{H}$, et al. Riociguat for interstitial lung disease and pulmonary hypertension: a pilot trial. Eur Respir J 2013; 41: 853-860.

93 Noth I, Zangan SM, Soares RV, et al. Prevalence of hiatal hernia by blinded multidetector CT in patients with idiopathic pulmonary fibrosis. Eur Respir J 2012; 39: 344-351.

94 Tobin RW, Pope CE 2nd, Pellegrini CA, et al. Increased prevalence of gastroesophageal reflux in patients with idiopathic pulmonary fibrosis. Am J Respir Care Med 1998; 158: 1804-1808.

95 Sweet MP, Patti MG, Leard LE, et al. Gastroesophageal reflux in patients with idiopathic pulmonary fibrosis referred for lung transplantation. J Thorac Cardiovasc Surg 2007; 133: 1078-1084.

96 Tcherakian C, Cottin V, Brillet PY, et al. Progression of idiopathic pulmonary fibrosis: lessons from asymmetrical disease. Thorax 2011; 66: 226-231.

97 Linden PA, Gilbert RJ, Yeap BY, et al. Laparoscopic fundoplication in patients with end-stage lung disease awaiting transplantation. J Thorac Cardiovasc Surg 2006; 131: 438-446.

98 Lee JS, Ryu JH, Elicker BM, et al. Gastroesophageal reflux therapy is associated with longer survival in patients with idiopathic pulmonary fibrosis. Am J Respir Crit Care Med 2011; 184: 1390-1394.

99 Raghu G, Meyer KC. Silent gastro-oesophageal reflux and microaspiration in IPF: mounting evidence for antireflux therapy? Eur Respir J 2012; 39: 242-245.

100 Cottin V, Nunes H, Brillet PY, et al. Combined pulmonary fibrosis and emphysema: a distinct under recognised entity. Eur Respir J 2005; 26: 586-593.

101 Mejia M, Carrillo G, Rojas-Serrano J, et al. Idiopathic pulmonary fibrosis and emphysema: decreased survival associated with severe pulmonary arterial hypertension. Chest 2009; 136: 10-15.

102 Cottin V, Le Pavec J, Prévot G, et al. Pulmonary hypertension in patients with combined pulmonary fibrosis and emphysema syndrome. Eur Respir J 2010; 35: 105-111.

103 Schmidt SL, Nambiar AM, Tayob N, et al. Pulmonary function measures predict mortality differently in IPF versus combined pulmonary fibrosis and emphysema. Eur Respir J 2011; 38: 176-183.

104 Akagi T, Matsumoto T, Harada T, et al. Coexistent emphysema delays the decrease of vital capacity in idiopathic pulmonary fibrosis. Respir Med 2009; 103: 1209-1215.

105 Clark M, Cooper B, Singh S, et al. A survey of nocturnal hypoxaemia and health related quality of life in patients with cryptogenic fibrosing alveolitis. Thorax 2001; 56: 482-486.

106 Aydogdu M, Ciftci B, Firat Guven S, et al. Interstisyel akciger hastalarinda polisomnografi ile uyku ozelliklerinin degerlendirilmesi [Assessment of sleep with polysomnography in patients with interstitial lung disease]. Tuberk Toraks 2006; 54: 213-221.

107 Mermigkis C, Chapman J, Golish J, et al. Sleep-related breathing disorders in patients with idiopathic pulmonary fibrosis. Lung 2007; 185: 173-178.

108 Lancaster LH, Mason WR, Parnell JA, et al. Obstructive sleep apnea is common in idiopathic pulmonary fibrosis. Chest 2009; 136: 772-778.

109 Recommandations pour la Pratique Clinique Syndrome d'apnées hyperpnées obstructives du sommeil de l'adulte [Recommendations for clinical practice. Obstructive sleep apnea hypopnea syndrome in adults]. Rev Mal Respir 2010; 27: 806-833.

110 Allen S, Raut S, Woollard J, et al. Low dose diamorphine reduces breathlessness without causing a fall in oxygen saturation in elderly patients with end-stage idiopathic pulmonary fibrosis. Palliat Med 2005; 19: 128-130.

111 Ekstrom MP, Bornefalk-Hermansson A, Abernethy AP, et al. Safety of benzodiazepines and opioids in very severe respiratory disease: national prospective study. BMJ 2014; 348: g445.

112 Morrison DA, Stovall JR. Increased exercise capacity in hypoxemic patients after long-term oxygen therapy. Chest 1992; 102: 542-550.

113 Visca D, Montgomery A, de Lauretis A, et al. Ambulatory oxygen in interstitial lung disease. Eur Respir J 2011; 38: 987-990.

114 Frank RC, Hicks S, Duck AM, et al. Ambulatory oxygen in idiopathic pulmonary fibrosis: of what benefit? Eur Respir J 2012; 40: 269-270.

115 Richeldi L, Ryerson CJ, Lee JS, et al. Relative versus absolute change in forced vital capacity in idiopathic pulmonary fibrosis. Thorax 2012; 67: 407-411.

116 Hubbard R, Venn A, Lewis S, et al. Lung cancer and cryptogenic fibrosing alveolitis. A population-based cohort study. Am J Respir Crit Care Med 2000; 161: 5-8. 
117 Turner-Warwick ME, Burrows B, Johnson A. Cryptogenic fibrosing alveolitis: clinical features and their influence on survival. Thorax 1980; 35: 171-180.

118 Harris JM, Johnston ID, Rudd R, et al. Cryptogenic fibrosing alveolitis and lung cancer: the BTS study. Thorax 2010; 65: 70-76.

119 Ozawa Y, Suda T, Naito T, et al. Cumulative incidence of and predictive factors for lung cancer in IPF. Respirology 2009; 14: 723-728.

120 Fell CD. Idiopathic pulmonary fibrosis: phenotypes and comorbidities. Clin Chest Med 2012; 33: 51-57.

121 Behr J. Evidence-based treatment strategies in idiopathic pulmonary fibrosis. Eur Respir Rev 2013; 22: 163-168.

122 Xaubet A, Behr J, Bendstrup E, et al. Review of IPF diagnosis and management recommendations in Europe. Sarcoidosis Vasc Diffuse Lung Dis 2013; 30: 249-261. 